\title{
Pseudohypoparathyroidism, Parkinsonism syndrome, with no basal ganglia calcification
}

\author{
BRADLEY K EVANS, DIANE K DONLEY
}

From the Department of Neurology, and Division of Pediatric Neurology, Department of Pediatrics, University of Alabama Medical School, Birmingham, AL, USA

SUMMARY A 20 year old woman with pseudohypoparathyroidism, Parkinsonism and no basal ganglia calcifications shown by computed tomography is reported. She has typical features of pseudohypoparathyroidism and biochemical evidence of end-organ resistance to parathyroid hormone. She is mentally retarded and has tremor, rigidity, bradykinesia, and stooped posture. The cause of Parkinsonism in pseudohypoparathyroidism is thought to be basal ganglia calcification. This patient must have another pathophysiology, perhaps directly related to a $G$ protein defect, causing impaired neurotransmission.

Basal ganglia calcification occurs frequently in parathyroid diseases. ${ }^{1}$ Since a Parkinsonism syndrome also occurs frequently in these diseases, it is thought that basal ganglia calcification causes Parkinsonism, although Lowenthal ${ }^{2}$ notes that "rigidity does not

Address for reprint requests: Bradley K Evans, MD, Department of Neurology, UAB Medical School, UAB Station, Birmingham, AL 35294, USA.

Received 28 August 1987.

Accepted 12 October 1987 coincide with the development of basal ganglia calcification."

We report a young girl with pseudohypoparathyroidism, a long-standing Parkinsonism syndrome, and no basal ganglia calcification revealed by computed tomography, showing that a Parkinsonism syndrome can occur in pseudohypoparathyroidism in the absence of calcification. It can be suspected on the basis of body type, family history, mental retardation, and signs of Parkinsonism alone.

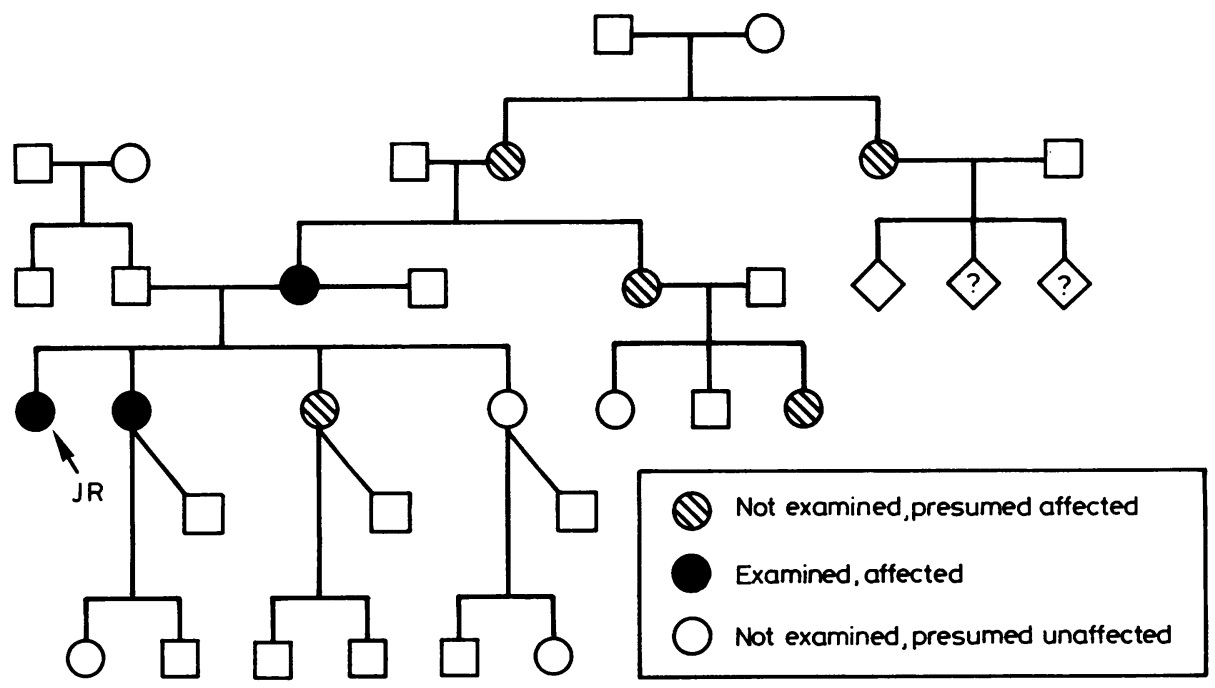

Fig 1 Family pedigree. 


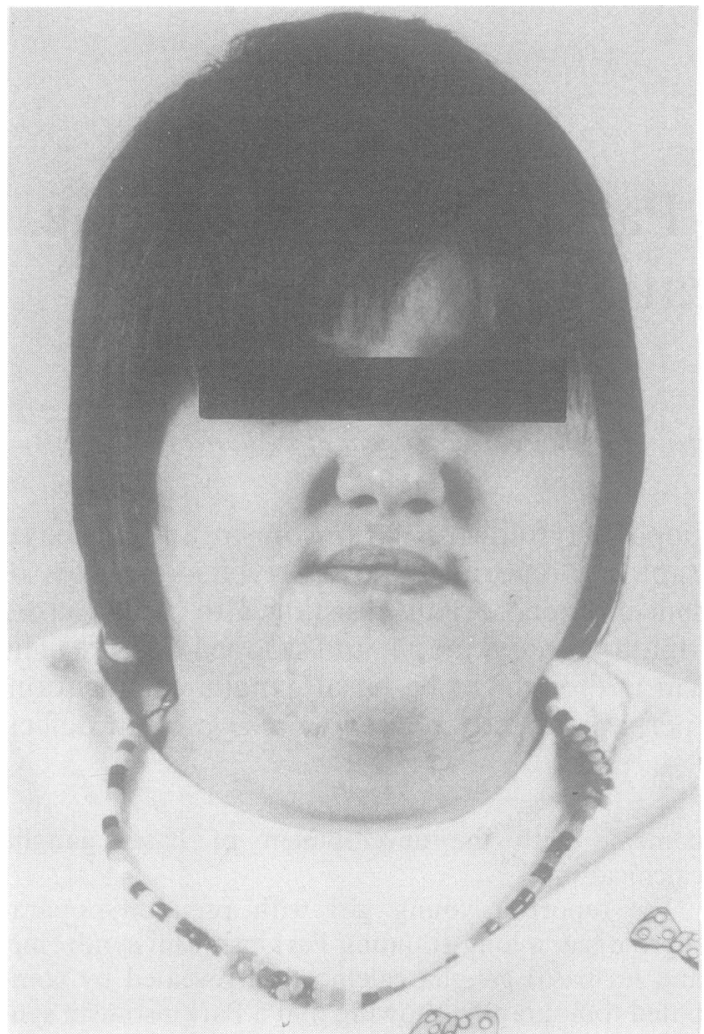

Fig 2 Face of patient.

\section{Case history}

This 20 year old woman with small stature, obesity, and mental retardation was the product of a normal pregnancy, with vaginal delivery. She weighed $2.5 \mathrm{~kg}$ at birth. She walked at 1 year, spoke sentences at 2 years, buttoned her clothes at 10 years and rode a bicycle at 11 years. She reads at the first grade level. Menses began at age 12 years. She has seen multiple physicians. One diagnosed "subclinical hypothyroidism" and prescribed thyroid hormone. Another prescribed oral calcium and vitamin D, for unclear reasons. A paediatric neurologist saw her at 12 years old. He found small stature, obesity, dental enamel abnormalities, small fingers and toes, mental retardation, rigidity, and mild tremor. CT of the head was normal. Bone age by radiography was 15 years. On WISC-R testing, VIQ was 47, PIQ 45, and FSIQ 41 . Many family members have similar problems (fig 1). All three sisters are short. Two have dental problems and short fingers and toes. One has "academic problems". Although the father is normal, the mother is short, mildly obese, and has dental abnormalities. Examination of the mother and one sister showed no Parkinsonism. The paternal grandmother has a Parkinsonism syndrome which began at age 55 years. The maternal grandmother is short and mentally retarded; her sister is short, obese, and was institutionalised because of mental retardation. A maternal aunt is short and obese; one of her daughters is mentally retarded, short, and obese.

On examination, she was $145.7 \mathrm{~cm}$ tall and weighed $78.1 \mathrm{~kg}$. Head circumference was $54.5 \mathrm{~cm}$. She had acne, oily skin, abdominal and breast striae, and excessive hair on the arms, thorax, abdomen, and face. She was Tanner Stage IV in sexual development. Her face was round (fig 2) and the neck short. She had many dental caries and many teeth had "fallen out". Fingers and toes were short with abnormal

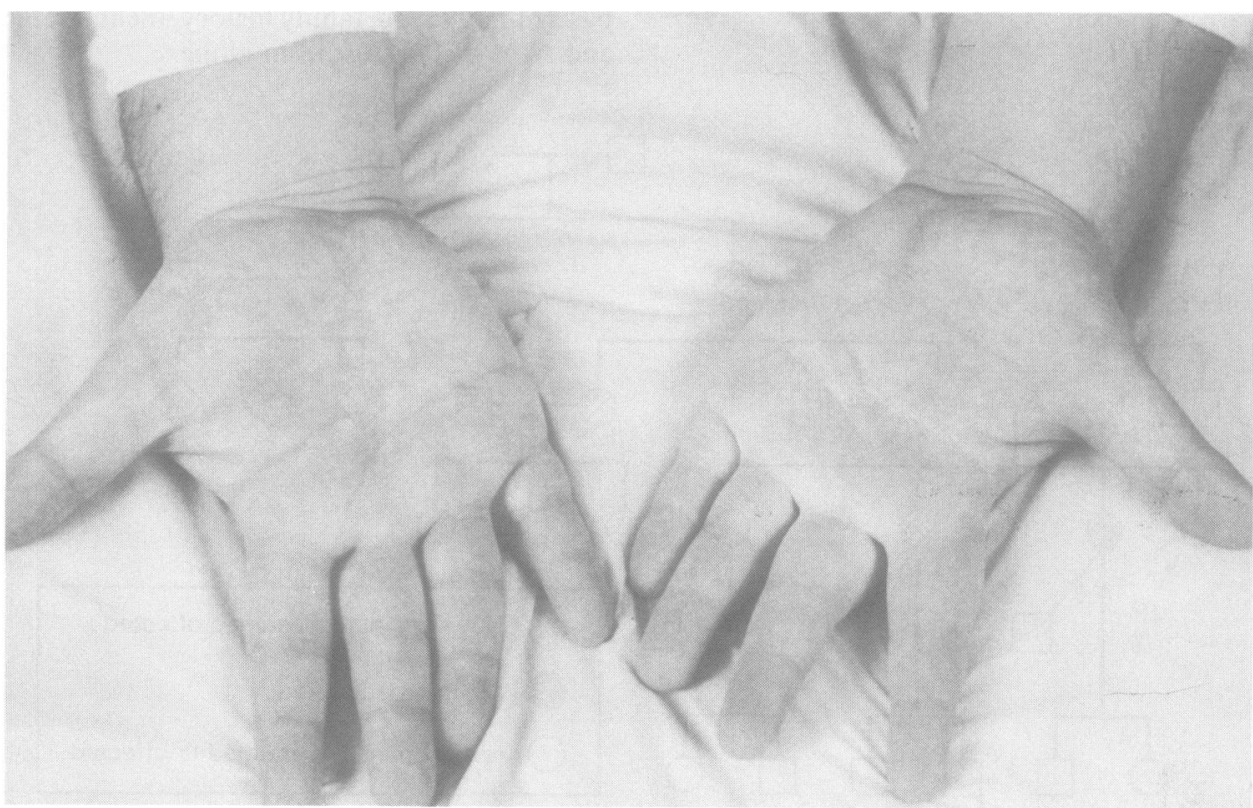

Fig 3 Hands, vertical view. 
creases (fig 3). On neurological examination, she was unable to tell time or make change. She had a snout reflex, Myerson's sign, tongue tremor, and jaw jerk. She had rigidity with cogwheeling, worse on the left. She had a resting supination-pronation tremor that became worse with sustentation. The feet were held inverted and the great toes dorsiflexed. There were no contractures. Knee and ankle jerks were mildly increased. There was no Babinski sign. She walked with a stooped posture, used small steps, and turned en bloc.

Serum total calcium was $9.8 \mathrm{mg} / \mathrm{dl}$, inorganic phosphates $4.7 \mathrm{mg} / \mathrm{dl}$ (normal $2 \cdot 2-4 \cdot 2 \mathrm{mg} / \mathrm{dl}$ ), and parathyroid hormone $69 \mathrm{pg} / \mathrm{ml}$ (normal $11-24 \mathrm{pg} / \mathrm{ml}$ ). T4, T3, and TSH levels were normal. Blood urea nitrogen, serum ceruloplasmin, prolactin, and creatinine were normal, as were all other blood tests. Chromosomes were normal female. Computed tomography showed cerebral atrophy and thickened calvarium, but no basal ganglia calcification. Electroencephalogram showed slowing of background activity and some low voltage beta activity. Repeat WISC-R showed VIQ 63, PIQ 58, FSIQ 60.

Because she had no complaints related to her Parkinsonism signs, we did not attempt treatment.

\section{Discussion}

Pseudohypoparathyroidism is characterised by the body type and by end-organ resistance to parathyroid hormone. ${ }^{3}$ Serum parathyroid hormone level in this patient was more than four standard deviations above the mean. Endocrinologists felt this confirmed endorgan resistance and the diagnosis of pseudohypoparathyroidism. They felt a parathyroid infusion test was both unnecessary and dangerous.

Fuller Albright first described pseudohypoparathyroidism in $1942,{ }^{4}$ emphasising body type, hypocalcaemia, and end-organ resistance to parathyroid hormone. In $1952,{ }^{5}$ he described patients with the body type but normal calcium level, calling it "pseudopseudohypoparathyroidism". Since that time, patients with intermittent hypocalcaemia have been described, ${ }^{6}$ as well as families with pseudohypoparathyroidism where some members had hypocalcaemia and others normal calcium level. ${ }^{7}$ Thus, separation of pseudohypoparathyroidism and pseudopseudohypoparathyroidism on the basis of serum calcium levels is probably specious and not useful. ${ }^{89}$

The pseudohypoparathyroid phenotype (Albright's hereditary osteodystrophy) is diagnostically useful. In this patient, the combination of body type, family history, mental retardation, and Parkinsonism led to the diagnosis despite normal calcium level and absence of basal ganglia calcification. The typical phenotype is short stature, round face, obesity, dental abnormalities, ${ }^{10}$ subcutaneous calcification, and short metacarpals and metatarsals. Bone age, by radiography, is advanced ${ }^{11}$ and the calvarium is thickened. Of the metacarpals, only the ring finger may be affected, causing dimpling over that knuckle when making a fist. ${ }^{5}$ The phenotype can be confused with Turner's syndrome. ${ }^{12} 13$

Variable expressivity, within families, of some disease manifestations, is seen in pseudohypoparathyroidism. This variability often involves the serum calcium level and the other endocrine manifestations. It may also include Parkinsonism, with some family members affected and others not. This is seen in this proband's family, probably in Spillane and Spillane's brothers, ${ }^{32}$ and perhaps in Hermans et al's family. ${ }^{33}$ The explanation for variable expressivity in pseudohypoparathyroidism is obscure.

The inheritance of pseudohypoparathyroidism is also obscure. ${ }^{3}$ Most families follow either $x$-linked dominant or autosomal dominant inheritance, with females preferentially affected. This patient's family is consistent with either type of inheritance.

In addition to parathyroid hormone resistance, pseudohypoparathyroid patients often have evidence of end-organ resistance to other hormones, especially $\mathrm{TSH}$, gonadotropins, and glucagon. ${ }^{14}$ Hormone resistance is probably due to a deficiency in $\mathrm{G}$ protein activity, ${ }^{3}$ although this is not proven. ${ }^{15} \mathrm{G}$ proteins, or guanine nucleotide-binding proteins, are a family of polyproteins that functions in transducing and amplifying a signal from a cell surface receptor (such as the parathyroid hormone receptor) to an effector molecule (adenylate cyclase in the case of parathyroid hormone).

$\mathrm{G}$ proteins may also function as intermediaries in the signal transmission of neurotransmitters as well as hormones. ${ }^{1617}$ In these cases, a $G$ protein would receive a signal from a cell surface receptor $(\alpha 2$ - and $\beta$-adrenergic, muscarinic, somatostatin, or GABA) ${ }^{17}$ and then excite or inhibit an effector molecule (adenylate cyclase, calcium channels, potassium channels, or phospholipase $C) .{ }^{1718}$ If the $G$ protein excites adenylate cyclase, it is called $G_{s}$; if it inhibits, $G_{i}$, and if no effect, $G_{0}$. These three types share protein subunits. Proteins and mRNAs for all three types of $G$ are present in brain. ${ }^{1920}$

Pseudohypoparathyroid patients often have anosmia. Weinstock $e t a^{21}$ have found that anosmia correlates with $G_{s}$ protein function, measured by an erythrocyte membrane $G_{s}$ reconstitution assay. Similarly, Farfel and Friedman ${ }^{22}$ found that mental retardation correlates with $G_{s}$ protein function, measured by the same assay. The $G_{s}$ protein defect may directly cause neurologic signs by altering neurotransmission.

Parkinsonism, although mentioned as occurring in $4-12 \%$ of pseudohypoparathyroid patients, ${ }^{2324}$ is rarely reported. Many reports involve elderly patients with recent-onset Parkinsonism and pseudohypo- 
parathyroidism. Pearson $e a^{25}$ reported a 58 year old woman with hypocalcaemia due to pseudohypoparathyroidism, basal ganglia calcification, and Parkinsonism that responded to calcium and vitamin D therapy. Felitti and McAfee ${ }^{26}$ and Money and Ehrhardt ${ }^{27}$ reported a 52 year old man with pseudohypoparathyroidism, hand tremor, stooped posture, and gait difficulties. Dihydrotachysterol therapy improved mental function and gait.

Others have reported young patients with pseudohypoparathyroidism and Parkinsonism. Reynolds et $a l^{28}$ reported a 29 year old man with a propulsive gait and stiff arms and legs. Alexander and Tucker's patient ${ }^{29}$ was a 49 year old man with recent "pillingrolling" tremor and stiffness dating back to age 25 years. Albright's group ${ }^{30}$ reported a 34 year old woman with rigidity and no tremor and MacGregor and Whitehead's ${ }^{31}$ case 1 , a man aged 23 , walked bent forward with a shuffling gait. They also noted that "several of the older patients showed signs of Parkinsonism, such as an immobile face, a lack of associated movements, and a propulsive gait. One also had tremor." Hermans et al $^{\mathbf{3 3}}$ reported a family with pseudopseudohypo-parathyroidism, of which three members (ages 31, 48, and 73 years) had a tremor, thought to be an essential tremor. None of the authors was a neurologist. Spillane and Spillane ${ }^{32}$ have a picture of a man with probable pseudohypoparathyroidism whose brother developed Parkinsonism at age 23 years and, later, basal ganglia calcification. Eaton et al's ${ }^{34}$ case 2, a 13-year-old boy with pseudohypoparathyroidism, had stammering, immobile facies, and decreased armswing.

Many of these young patients have no symptoms related to Parkinsonism. This lack of complaints and the physician's tendency to attribute rigidity, postural disturbances, bradykinesia, and tremor to hypothyroidism, hypocalcaemia, or mental retardation may lead to an underreporting of Parkinsonism in pseudohypoparathyroid patients.

Our patient had tremor, rigidity, bradykinesia, and a postural disturbance diagnostic of Parkinsonism even though she had no complaints related to these abnormalities. The abnormalities were present 8 years apart in examinations done by two different paediatric neurologists.

The pathophysiology of her Parkinsonism signs could be due to the coexistence of juvenile Parkinsonism and pseudohypoparathyroidism or could be related to pseudohypoparathyroidism itself, possibly due to undetectable basal ganglia calcification, undetected episodes of hypocalcaemia, the effect of end-organ resistance to an unknown hormone, or a deficiency of a $\mathrm{G}$ protein function causing impaired neuro-transmission.

Dr Arnold Gold saw the patient at age 12 years and provided his case notes. Endocrinologists were Drs Maria New and Joseph Gertner. This paper first appeared as an abstract (\#212) in the Child Neurology Society Meeting, October, 1986.

\section{References}

1 Illum F, Dupont R. Prevalences of CT-detected calcification in the basal ganglia in idiopathic hypoparathyroidism and pseudohypoparathyroidism. Neuroradiology 1985;27:32-37.

2 Lowenthal A. Stripallidodentate calcifications. In: Vinken PJ, Bruyn GW, Klawans HL, eds. Handbook of Clinical Neurology Vol. 49 revised series 5, Extrapyramidal Disorders. Amsterdam: Elsevier, 1986.

3 Drezner MK, Neelon FA. Pseudohypoparathyroidism. In: Stanbury JB, Wyngaarden JB, Frederickson DS, Goldstein JL, Brown MS eds. The Metabolic Basis of Inherited Disease, 5th ed. New York: McGraw-Hill, 1983.

4 Albright F, Burnett $\mathrm{CH}$, Smith PH, Parson W. Pseudohypoparathyroidism - an example of the "Seabright-Bantam" syndrome. Report of three cases. Endocrinology 1942;30:922-32.

5 Albright F, Forbes AP, Henneman H. Pseudo-pseudohypoparathyroidism. Trans Assoc Am Phys 1952;65: $337-50$.

6 Breslau NA, Nofman DD, Canterbury JM, Moses AM. Studies on the attainment of normocalcemia in patients with pseudohypoparathyroidism. Am J Med 1980;68:856-60.

7 Mann JB, Alterman S, Hills AG. Albright's hereditary osteodystrophy comprising pseudohypoparathyroidism and pseudo-pseudohypoparathyroidism. Ann Int Med 1962;56:315-42.

8 Drezner MK, Haussler MR. Normocalcemic pseudohypoparathyroidism. Association with normal vitamin $\mathrm{D}_{3}$ metabolism. Am J Med 1979;66:503-8.

9 Balachandar V, Pahuja J, Maddiah VT, Collipp PJ. Pseudohypoparathyroidism with normal serum calcium level. Am J Dis Child 1975;129:1092-5.

10 Ritchie G MacL. Dental manifestations of pseudohypoparathyroidism. Arch Dis Child 1965;40:565-72.

11 Monn E, Osnes JB, Oye I, Wefring KW. Pseudohypoparathyroidism: a difficult diagnosis in early childhood. Acta Paediatr Scand 1976;65:487-93.

12 van der Werfften Bosch JJ. The syndrome of brachymetacarpal dwarfism ("pseudo-pseudohypoparathyroidism") with and without gonadal dysgenesis. Lancet 1959;i:69-71.

13 Miller JQ, Rostafinski MJ, Hyde MA. Gonadal dysgenesis and bradymetacarpal dwarfism (pseudopseudohypoparathyroidism). Arch Intern Med 1965;116:940-3.

14 Levine MA, et al. Resistance to multiple hormones in patients with pseudohypoparathyroidism. Am J Med 1983;74:545-56.

15 Editorial. Pseudohypoparathyroidism: continuing paradox. Lancet 1983;ii:439-40.

16 Gilman AG. G proteins and dual control of adenylate cyclase. Cell 1984;36:577-9.

17 Bourne HR. GTP-binding proteins: one molecular 
machine can transduce diverse signals. Nature 1986;321:814-6.

18 Smith CD, Cox CC, Snyderman R. Receptor-coupled activation of phosphoinositidespecific phospholipase $C$ by an $N$ protein. Science $1986 ; 232: 97-100$.

19 Mumby SM, Kahn RA, Manning DR, Gilman AG. Antisera of designed specificity for subunits of guanine nucleotide-binding regulatory proteins. Proc Natl Acad Sci USA 1986;83:265-9.

20 Harris BA, Probishaw JD, Mumby SM, Gilman AG. Molecular cloning of complementary DNA for the alpha subunit of the $G$ protein that stimulates adenylate cyclase. Science 1985;229:1274-7.

21 Weinstock RS, Wright HN, Spiegel AM, Levine MA, Moses AM. Olfactory dysfunction in humans with deficient guanine nucleotide-binding protein. Nature 1986;322:635-6.

22 Farfel Z, Friedman E. Mental deficiency in pseudohypoparathyroidism type I is associated with Ns-protein deficiency. Ann Int Med 1986;105:197-9.

23 Bronsky D, Kushner DS, Dublin A, Snapper I. Idiopathic hypoparathyroidism and pseudohypoparathyroidism: case reports and review of the literature. Medicine 1958;37:317-52.

24 Frame B. Neuromuscular manifestations of parathyroid disease. In: Vinken PJ, Bruyn GW, eds. Handbook of Clinical Neurology, Vol. 27. Metabolic of Deficiency Diseases of the Nervous System. Amsterdam: Elsevier, 1976.

25 Pearson DWM, Durward WF, Fogelman I, Boyle IT,
Beastall G. Pseudohypoparathyroidism presenting as severe Parkinsonism. Postgrad Med J 1981;57:445-7.

26 Felitti VJ, McAfee LL. Recovery from symptoms in pseudohypoparathyroidism. Johns Hopkins Med J 1968;123:271-5.

27 Money J, Ehrhardt AA. Correlation of mental functioning and calcium regulation in a rare case of pseudohypoparathyroidism. Johns Hopkins Med J 1968;123:276-82.

28 Reynolds TB, et al. Pseudohypoparathyroidism: Report of a case showing bony demineralization. $J$ Clin Endocrinol Metab 1952;12:560-73.

29 Alexander SD, Tucker H St G Jr. Pseudohypoparathyroidism. Report of a case with late manifestations. $J$ Clin Endocrinol 1949;9:862-72.

30 Elrick H, Albright F, Bartter FC, Forbes AP, Reeves JD. Further studies on pseudohypoparathyroidism: report of four new cases. Acta Endocrinol 1950;5:199-225.

31 MacGregor ME, Whitehead TP. Pseudohypoparathyroidism. Arch Dis Childhood 1954;29:398-418.

32 Spillane JD, Spillane JA. An Atlas of Clinical Neurology. Oxford: Oxford University Press, 1982;371-2.

33 Hermans PJ, Gorman CA, Martin WJ, Kelly PJ. Pseudo-pseudohypoparathyroidism (Albright's hereditary osteodystrophy): A family study. Mayo Clin Proc 1964;39:81-91.

34 Eaton L, Camp JD, Love JG. Symmetric cerebral calcifications particularly of the basal ganglia demonstrable radiographically. Arch Neur Psych 1939;41: 921-42. 